\title{
Development of FK506-hyperproducing strain and optimization of culture conditions in solid-state fermentation for the hyper-production of FK506
}

\author{
SangJoon $\mathrm{Mo}^{1}$ (D) $\cdot$ Hyeong Seok Yang ${ }^{2}$
}

Received: 31 May 2016 / Accepted: 20 July 2016 / Published Online: 31 December 2016

(C) The Korean Society for Applied Biological Chemistry 2016

\begin{abstract}
FK506 hyper-yielding mutant, called the TCM8594 strain, was made from Streptomyces tsukubaensis NRRL 18488 by mutagenesis using $N$-methyl- $N$ '-nitro- $N$-nitrosoguanidine, ultraviolet irradiation, and FK506 sequential resistance selection. FK506 production by the TCM8594 strain improved 45.1-fold $(505.4 \mu \mathrm{g} /$ $\mathrm{mL})$ compared to that of $S$. tsukubaensis NRRL $18488(11.2 \mu \mathrm{g} /$ $\mathrm{mL}$ ). Among the five substrates, wheat bran was selected as the best solid substrate to produce optimum quantities of FK506 $(382.7 \mu \mathrm{g} / \mathrm{g}$ substrate) under solid-state fermentation, and the process parameters affecting FK506 production were optimized. Maximum FK506 yield ( $897.4 \mu \mathrm{g} / \mathrm{g}$ substrate) was achieved by optimizing process parameters, such as wheat bran with $5 \%(\mathrm{w} / \mathrm{w})$ dextrin and yeast extract as additional nutrients, $70 \%(\mathrm{v} / \mathrm{w})$ initial solid substrate moisture content, initial medium $\mathrm{pH}$ of $7.2,30{ }^{\circ} \mathrm{C}$ incubation temperature, inoculum level that was $10 \%(\mathrm{v} / \mathrm{w})$ of the cell mass equivalent, and a 10 day incubation. The results showed an overall $234 \%$ increase in FK506 production after optimizing the process parameters.
\end{abstract}

Keywords FK506 - Immunosuppressant $\cdot$ Solid-state fermentation - Streptomyces tsukubaensis · Wheat bran

SangJoon Mo $(\varangle)$

E-mail:sjmo1107@dankook.ac.kr

${ }^{1}$ Biosafety \& Validation Center, Clinical Trial Institute, Dankook University, 119 Dandae-ro, Dongnam-gu, Choenan-si, Chungnam, 31116, Republic of Korea

${ }^{2}$ Department of Medical Laser, Graduate School of Dankook University, Choenan, 31116, Republic of Korea

This is an Open Access article distributed under the terms of the Creative Commons Attribution Non-Commercial License (http://creativecommons. org/licenses/by-nc/3.0/) which permits unrestricted non-commercial use, distribution, and reproduction in any medium, provided the original work is properly cited.

\section{Introduction}

Tacrolimus (FK506) has been used for patents undergoing organ and tissue transplants (Haddad et al. 2006). In particular, among the different commercially available immunosuppressant agents (cyclosporine, rapamycin, and mycophenolate), FK506 is one of the potent immunosuppressive agent to treat transplants rejection, marketed by Astellas under the name Prograf, which represented $27.6 \%$ of annual immunosuppressant market sales in 2011 (Martínez-Castro et al. 2013). Recently, FK506 is also used for treatment atopic dermatitis and autoimmune disorder in recently (Barreiro and Martínez-Castro 2014). To meet the increasing demand for FK506, researchers have attempted to develop high producing strains and fermentation processes to produce FK506 more efficiently and economically (Yang et al. 2014). However, there are restraints on using high-yielding FK506 strains by companies that hold the patent for strain development. Hence, since FK506 was first isolated from the filamentous bacterium $S$. tsukubaensis in 1987, 18 FK506 producer strains have been reported to overcome this problem until now (Barreiro and Martínez-Castro 2014).

Random mutagenesis is the easiest and powerful tool to improve a strain. Ultraviolet (UV)-rays, X-rays, gamma-rays, lasers, neutrons, methyl methane sulfonate, hydroxyl amines, and $N$-methyl- $N$ nitro- $N$-nitrosoguanidine (NTG) have been extensively used as mutagenesis agents. NTG is able to lead to GC-AT transition mutations, which limits its usefulness in generalized mutagenesis (Baltz 1986a; b). In contrast, UV radiation is among the most effective, simple, and safe mutagenic agents. UV induces a broad range of single base mutations in Escherichia coli (Miller 1983) but knowns to be a weak mutagenicity in Streptomyces (Baltz 1986a; b). However, quite a lot of antibiotics have been procured from various high yielding mutants after treating Streptomyces spp. with UV irradiation. In particular, Xu et al. (2005) achieved three-fold increase in rapamycin yield by Streptomyces hygroscopicus HD-04-S after UV mutagenesis (Xu et al. 2005). 
Recently, a lot of solid-state fermentation (SSF) processes are used to produce microbial metabolites, including chemicals, enzymes, antibiotics, and immunosuppressants because of the many benefit over traditional submerged fermentation $(\mathrm{SmF})$ (Kota and Sridhar 1998; Ellaiah et al. 2004; Rajoka et al. 2006). SSF is simpler, requires less working capital, results in superior productivity, reduces energy consumption, uses uncomplicated fermentation media, does not require exact parameters to control the fermentation, reduces water use, produces less wastewater, is easier to control microbial contamination, and requires lower cost for purification processing compared to those of SmF (Ghildyal et al. 1985). The significant constituents that affect the synthesis of bacterial secondary metabolites in a SSF system include selecting a proper substrate and microbe, pretreating the substrate, substrate particle size, substrate water content, relative humidity of culture environment, inoculum type and size, control of generation of heat in matter, fermentation duration, maintenance of $\mathrm{O}_{2}$ consumption and $\mathrm{CO}_{2}$ emission rates (Ghildyal et al. 1985; Rajoka et al. 2006; El-Naggar et al. 2009).

In this study, we studied the ability of a high yielding FK506 mutant obtained after NTG and UV mutagenesis of S. tsukubaensis NRRL 18488 to enhance FK506 production. We also defined various fermentation parameters necessary to maintain mutants that produced higher levels of FK506 under SSF. The production of FK506 by S. tsukubaensis under SSF conditions has not been reported before now.

\section{Materials and Methods}

\section{Bacterial strain, culture conditions, and materials}

S. tsukubaensis NRRL 18488 (wild-type) was obtained from the Agricultural Research Service Culture Collection (NRRL, Peoria, IL, USA) and its mutant (TCM8594) was developed after sequential FK506 resistance selection followed by NTG and UV mutagenesis and was used in this study. Wild-type and TCM8594 strains were grown on ISP4 plates at $28{ }^{\circ} \mathrm{C}$ for 6 days for complete sporulation and prepare the inoculum. The spore suspension of wild-type and TCM8594 was inoculated for seed culture into a baffled flask (250 mL) containing $50 \mathrm{~mL}$ of seed medium $(0.5 \%$ glucose, $1 \%$ soluble starch, $0.5 \%$ yeast extract, $0.25 \%$ corn steep powder, 1 $\%$ glycerol, and $0.1 \% \mathrm{CaCO}_{3}, \mathrm{pH} 7.2$ ), and the baffled flask was then fermented at $28{ }^{\circ} \mathrm{C}$ for 3 days in an orbital shaking incubator at $180 \mathrm{rpm}$ to develop the seed culture, respectively. Subsequently, $10 \%(\mathrm{v} / \mathrm{v})$ of the above seed culture was transferred to $250 \mathrm{~mL}$ baffled flasks containing $50 \mathrm{~mL}$ modified production medium (7.5 $\%$ dextrin, $2 \%$ dried yeast powder, $0.5 \%$ corn steep powder, 0.5 $\% \mathrm{~K}_{2} \mathrm{HPO}_{4}$, and $0.05 \% \mathrm{CaCO}_{3}, \mathrm{pH} 7.2$ ), and fermentation was carried out on an orbital shaking incubator at $180 \mathrm{rpm}$ and $28{ }^{\circ} \mathrm{C}$ for 7 days according to the methods Martínez-Castro et al. (2013).
Strain development and screening study for the FK506 highyielding strain

Wild-type spore suspensions $\left(10^{8}\right.$ spores $\left./ \mathrm{mL}\right)$ were processed with NTG $(0.5-5 \mathrm{mg} / \mathrm{L})$ in Tris/malate buffer $(50 \mathrm{mM}$, pH 9.0) for 60 min, collected by filtration, washed three times with sterile saline, and plated on Bennett's (BN) agar plates for 5 days at $28{ }^{\circ} \mathrm{C}$. The resulting colonies were overlaid with soft $(7 \%$, w/v) malt extract agar seeded with $10^{5}$ cells $/ \mathrm{mL}$ of Aspergillus niger ATCC 6275 . After $48 \mathrm{~h}$ cultivation at $28^{\circ} \mathrm{C}$, colonies with large zone of fungal inhibition were selected. These colonies were stabilized on ISP4 plates, and the spores were collected again using the method described above. The spores were diluted and plated on BN agar plates, and the open plates were UV irradiated for $30-120 \mathrm{~s} 30 \mathrm{~cm}$ from UV $(253.7 \mathrm{~nm} / 30 \mathrm{~W})$. The BN agar plates were incubated under the same conditions described above for overlay-selection. After $48 \mathrm{~h}$ incubation at $28{ }^{\circ} \mathrm{C}$, colonies showing wide inhibition zones were selected (Lee et al. 2003). These colonies with wide inhibition zones were cultivated on ISP4 medium for spore formations. The spores were smeared on agar medium plates with $50 \mu \mathrm{g} / \mathrm{mL}$ FK506 for sequential adaptation and incubated at $28{ }^{\circ} \mathrm{C}$ for 5 days. Among the strains with resistant to FK506, an FK506 high-yielding strain was screened using the $A$. niger bioassay and high performance liquid chromatography (HPLC) analysis according to the methods of Mo et al. (2013). The calibration curve of FK506 was created using an FK506 standard (Sigma-Aldrich, USA). The calibration curve for quantitative analysis of FK506 is shown in Supplementary Fig. 1 in the supplement materials.

The concentration of FK506 eventually increased to a final concentration of $500 \mu \mathrm{g} / \mathrm{mL}$ on FK506 resistance selection agar plates. The detailed procedure for the development of FK506 high-yielding strain by random mutagenesis and sequential FK506 resistance selection is illustrated in Fig. 1.

\section{Gene expression analysis by semi-quantitative RT-PCR}

For RNA isolation, wild-type and TCM8594 strains were grown on R2YE medium for $72 \mathrm{~h}$. Mycelia of wild-type and TCM8594 were harvested and immediately stabilized in RNAprotect Bacteria Reagent (Qiagen, Valencia, CA, USA), and suspensions were kept at $-80{ }^{\circ} \mathrm{C}$. Total RNA was extracted according to the manufacturer's protocol by using a RNeasy mini kit (Qiagen). The RNA quantity and quantity were measured via a NanoDrop 2000 UV-Vis spectrophotometer (Thermo Fisher Scientific, Waltham, MA, USA) and agarose gel electrophoresis. RT-PCR was carried out by OneStep RT-PCR kit (Qiagen) using $1 \mu \mathrm{g}$ of total RNA as a template. The conditions were as follows: for first stand cDNA synthesis, $50{ }^{\circ} \mathrm{C}$ for $30 \mathrm{~min}$, followed by $95{ }^{\circ} \mathrm{C}$ for $15 \mathrm{~min}$; for PCR amplification, 35 or 38 cycles of $97^{\circ} \mathrm{C}$ for $1 \mathrm{~min}, 60-70{ }^{\circ} \mathrm{C}$ (depending on the set of primers used) for $1 \mathrm{~min}, 74^{\circ} \mathrm{C}$ for $1 \mathrm{~min}$, and a final elongation step of $5 \mathrm{~min}$ at $75^{\circ} \mathrm{C}$. All primers used for RT-PCR amplification are shown in Supplementary Table 1 in the 


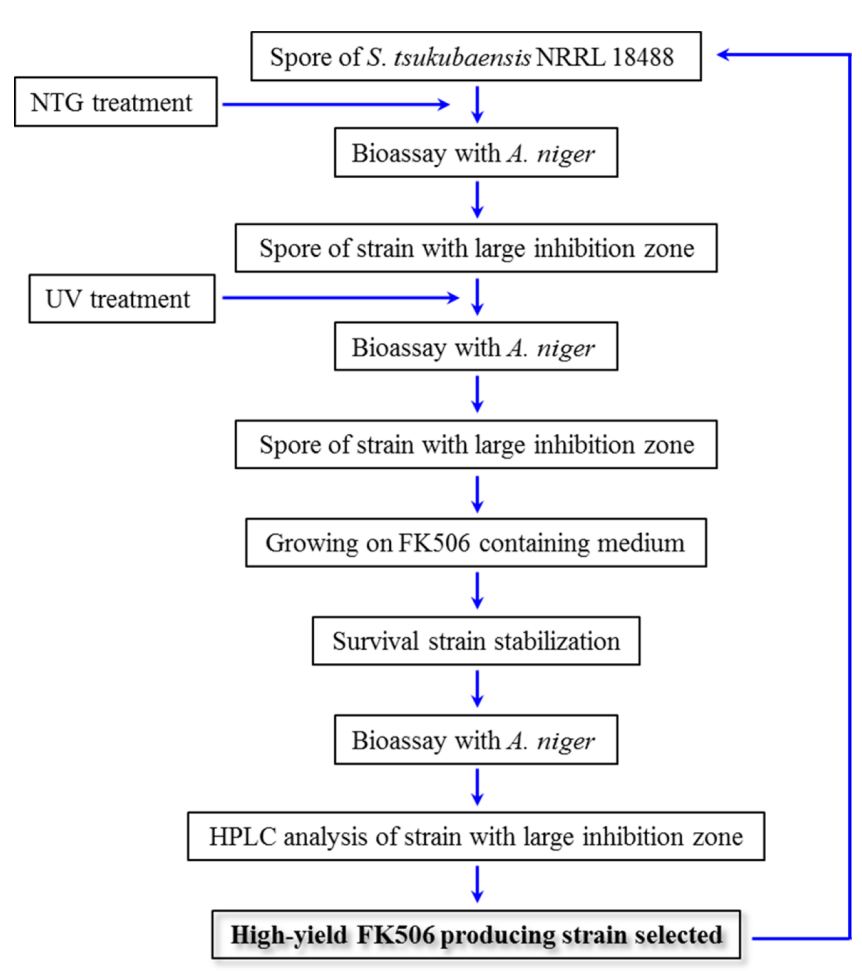

Fig. 1 Development strategies of high-yield FK506 producing strain via repeated and sequential mutagenesis and HPLC analysis of developed strain. Flow charts for development of FK506 high-yielding strain by random mutagenesis and sequential FK506 resistance selection

supplement materials. Negative control (the absence of reverse transcriptase) experiments were performed to check for DNA contamination in the RNA preparations. The 16S rRNA were used as positive markers for RNA quality (Mo et al. 2016). All experiments were performed in duplicate RNA sample, using two independent cultures.

\section{Optimization of SSF}

Factors affecting FK506 production by wild-type and TCM8594 strain were optimized in wide mouth Erlenmeyer flasks $(500 \mathrm{~mL})$ each containing $20 \mathrm{~g}$ of substrate (wheat bran, rice husk, rice bran, sesame oil cake, and soy flour) and $2 \mathrm{~mL}$ of element solution in triplicate. The composition of the element solution was (w/v): $0.05 \% \mathrm{KH}_{2} \mathrm{PO}_{4}, 1.0 \% \mathrm{MgCl}_{2} \cdot 6 \mathrm{H}_{2} \mathrm{O}, 1 \% \mathrm{CaCl}_{2} \cdot 2 \mathrm{H}_{2} \mathrm{O}, 0.05 \%$ $\mathrm{FeCl}_{3} \cdot 6 \mathrm{H}_{2} \mathrm{O}$, and $0.05 \% \mathrm{ZnCl}_{2}$. Experiments were carried out in wide mouth Erlenmeyer flasks (500 mL) containing $20 \mathrm{~g}$ substrate moistened with distilled water to produce $50 \%(\mathrm{v} / \mathrm{w})$ moisture content. Initial $\mathrm{pH}$ was adjusted to 7.2, the Erlenmeyer flasks were plugged with non-absorbent cotton, and autoclaved for $20 \mathrm{~min}$ at $121{ }^{\circ} \mathrm{C}$ (Khaliq et al. 2009). After cooling the substrate at room temperature, $10 \%(\mathrm{v} / \mathrm{w})$ of a 3-day old seeding culture was inoculated, and the flasks were fermented at $28{ }^{\circ} \mathrm{C}$ for 12 days under appropriate experimental conditions. After fermentation, samples (three whole flasks) were analyzed the FK506 production by HPLC.
Table 1 Improved FK506 production by random mutations of $S$. tsukubaensis NRRL 18488

\begin{tabular}{cccc}
\hline $\begin{array}{c}\text { Mutagenic } \\
\text { treatment round }\end{array}$ & Mutant & $\begin{array}{c}\text { FK506 } \\
\text { production } \\
(\mu \mathrm{g} / \mathrm{mL})^{\mathrm{b}}\end{array}$ & $\begin{array}{c}\text { Relative } \\
\text { productivity } \\
(\text { fold })\end{array}$ \\
\hline $\begin{array}{c}\text { None } \\
1^{\text {st }} \mathrm{NTG}+\mathrm{UV}\end{array}$ & Control & $11.2 \pm 0.6$ & 1 \\
$2^{\text {nd }} \mathrm{NTG}+\mathrm{UV}$ & TCM935 & $25.1 \pm 0.9$ & 2.2 \\
$3^{\text {rd }} \mathrm{NTG}+\mathrm{UV}$ & TCM2104 & $75.4 \pm 1.1$ & 6.7 \\
$4^{\text {th }} \mathrm{NTG}+\mathrm{UV}$ & TCM3174 & $219.3 \pm 4.7$ & 12.7 \\
$5^{\text {th }} \mathrm{NTG}+\mathrm{UV}$ & TCM4817 & $296.5 \pm 9.2$ & 19.6 \\
$6^{\text {th }} \mathrm{NTG}+\mathrm{UV}$ & TCM6048 & $353.8 \pm 10.9$ & 26.5 \\
$7^{\text {th }} \mathrm{NTG}+\mathrm{UV}$ & TCM7129 & $431.7 \pm 12.4$ & 31.6 \\
$8^{\text {th }} \mathrm{NTG}+\mathrm{UV}$ & TCM8594 & $505.4 \pm 11.7$ & 45.1 \\
\hline
\end{tabular}

${ }^{\mathrm{a}}$ The strain was developed by NTG treatment and UV irradiation to obtain a superior strain combined with cultivation on medium containing stepwise increasing concentrations of FK506

${ }^{\mathrm{b}}$ The mycelia were collected on filter paper by vacuum filtration after a 6 day cultivation. Cell-free culture broth was extracted twice with equal volumes of ethyl acetate. The organic extract was evaporated to dryness under reduced pressure and dissolved in $0.2 \mathrm{~mL}$ methanol for the HPLC analysis. The level of FK506 production reported is the mean of two series of duplicate separate cultivations and extractions

\section{Optimization of process parameters for FK506 production in SSF}

The influence of various physicochemical and nutritional parameters on FK506 production was investigated. Wheat bran was used as the best substrate for FK506 production in all studies. Moisture contents of 20, 30, 40, 50,60,70, and $80 \%(\mathrm{v} / \mathrm{w})$ and incubation times of $1,2,3,4,5,6,7,8,9,10,11$, and 12 days as well as inoculum levels of $2,5,10,15$, and $20 \%(\mathrm{v} / \mathrm{w})$ of a 3 -day old seeding culture were investigated. Incubation $\mathrm{pH}$ of the medium was studied between 4 and 9 . The $\mathrm{pH}$ was adjusted with $0.5 \mathrm{~N} \mathrm{NaOH}$ or $\mathrm{HCl}$. The effects of temperatures on FK506 production were investigated at $25,30,35,40$, and $45^{\circ} \mathrm{C}$. Studies were also conducted to examine the effects of various carbon and nitrogen sources supplemented into the wheat bran solid culture on FK506 production. The effect of adding $5 \%(\mathrm{w} / \mathrm{w})$ carbon sources (glucose, lactose, maltose, mannose, sorbitol, sucrose, starch, and dextrin) was evaluated using appropriate culture conditions (Asagbra et al. 2005; El-Naggar et al. 2009; Khaliq et al. 2009). Also more studies were conducted to determine the significance of various organic nitrogen sources (yeast extract, tryptone, peptone, casamino acids, soytone, malt extract, and corn steep powder at $1 \mathrm{~g} / 20 \mathrm{~g}$ substrate) in the existence of wheat bran and dextrin on FK506 production (Khaliq et al. 2009). SSF was carried out at $30{ }^{\circ} \mathrm{C}$ for 12 days under optimal fermentation conditions (initial $\mathrm{pH}$ of 7.2, initial moisture content of $70 \%(\mathrm{v} / \mathrm{w})$, inoculum level of $10 \%$ (v/w, 3-day old seeding culture). Each experiment was conducted in triplicate.

FK506 extraction and HPLC analysis

The cell biomass was homogenized with three volumes of 
methanol by blender after SSF. The sample was kept on rotary shaker $(180 \mathrm{rpm})$ for $3 \mathrm{~h}$. After centrifugation, the extract was then filtered with filter paper (Advantech 5A) and $0.45 \mu \mathrm{m} \mathrm{GD/XP}$ nylon syringe filter (GE Healthcare, Clifton, NJ, USA) to remove additional fine particles and obtain a clear solution. The extract (2 $\mathrm{mL}$ ) was evaporated to dryness in a speed vacuum concentrator. The dried extract was dissolved in $0.2 \mathrm{~mL}$ methanol, and FK506 was estimated by HPLC as mentioned above.

\section{Antifungal assay of SmF and SSF}

Samples of SmF and SSF were extracted twice with ethyl acetate and methanol, respectively. The crude extracts were dried using an evaporator. The dried SmF and SSF extracts were redissolved in methanol to make a concentration of $100 \mathrm{mg} / \mathrm{mL}$. Methanol was served as a negative control and $1 \mathrm{mg} / \mathrm{mL}$ of Amphotericin B (Sigma-Aldrich, USA) was served as a positive control for this assay. Sterile paper discs ( $8 \mathrm{~mm}$ in diameter, Advantec Co., Tokyo, Japen) were impregnated with $4 \mathrm{mg}(40 \mu \mathrm{L})$ of each extract. Cell suspension of $A$. niger (at a concentration of $10^{5}$ cells $/ \mathrm{mL}$ ) was spread onto the surface of potato dextrose agar (BD Difco, Sparks, MD, USA) media before additional of the impregnated papers discs. The inhibition zone diameter of around the discs was measured after incubating fungal plates at $28{ }^{\circ} \mathrm{C}$ in the dark for 24 $\mathrm{h}$. This assay was done in three replicates.

\section{Results and Discussion}

\section{Selection of FK506 high-yielding strain by random mutagenesis} and FK506 resistance selection

S. tsukubaensis NRRL 18488 spores were subjected to NTG, UV, and sequential FK506 resistance selection to improve an FK506 yield of mutants. A number of colonies obtained after NTG treatment of the wild-type strain were preliminarily screened for a wide inhibition zone against $A$. niger, and the spores of selected colonies were UV irradiated. The rates of survival of the parent strain after the $3 \mathrm{mg} / \mathrm{mL}$ NTG treatment for $1 \mathrm{~h}$ and UV irradiation for $120 \mathrm{~s}$ were 10 and $1 \%$, respectively. Among them, colonies with the maximum diameters of growth inhibition zone against $A$. niger were smeared on agar medium plates containing FK506. An FK506 resistance colonies were isolated in a growth medium containing FK506, and the mutant strains with the highest FK506 yields were selected using the agar plug method and HPLC analysis. One colony with the largest inhibitory zone diameter against $A$. niger was selected from 418 FK506 resistance colonies and designated TCM324. The TCM324 mutant strain increased FK506 yield by approximately 2.2 -fold $(25.1 \mu \mathrm{g} / \mathrm{mL})$ compared with that by the wild-type strain $(11.2 \mu \mathrm{g} / \mathrm{mL}$; Table 1$)$. The TCM8594 mutant strain, which was selected after eight selection rounds among 10,798 mutagenized colonies after NTG treatment, UV irradiation, and sequential FK506 resistance selection, showed the highest FK506 production, and increased
FK506 yield by approximately 45.1 -fold ( $505.4 \mu \mathrm{g} / \mathrm{mL})$ compared with that from wild-type strain $(11.2 \mu \mathrm{g} / \mathrm{mL}$; Table 1$)$ without any improvement in biomass yield. This result shows that NTG and UV were the most powerful and efficient methods to generate the optimal FK506 yield from the mutants. Furthermore, the FK506 yield by the TCM8594 strain increased to $505.4 \mu \mathrm{g} / \mathrm{mL}$, which was close to that observed by $S$. tsukubaensis CZ-19 previously (Yang et al. 2014).

Transcription level analysis of $t c s B, f k b B$, and $f k b N$ genes in wild-type and TCM8594 strains

To investigate the difference in expression profiles of $t c s B, f k b B$, and $f k b N$ transcripts level, transcription analysis of these genes was conducted by semi-quantitative RT-PCR in the wild-type and TCM8594 strains. This was because these genes are an essential gene for FK506 biosynthesis (Mo et al. 2012). Total RNA was isolated from the wild-type and TCM8594 strains after 24, 48, and $72 \mathrm{~h}$ of cultivation and was prepared as the template for analysis of gene expression level by RT-PCR. All primers were specific to the sequences within the $t c s B, f k b B$, and $f k b N$ genes and were designed to amplify approximately $500 \mathrm{bp}$ of each cDNAs (Supplementary Table 1). The levels of the unrelated transcript, constitutively expressed 16S rRNA gene, assayed as a control for RNA purity, integrity and loading levels, did not change culture times. The Fig. 2 presents the results of these RT-PCR experiments. The transcripts of these genes were not observed a change at any point during a 3-day time course using semi-quantitative RT-PCR in the wild-type strain, suggesting that these genes might constant the onset of FK506 biosynthesis. While the transcripts of these genes increased slowly during $24 \mathrm{~h}$ of fermentation and relatively quickly between hours 48 and $72 \mathrm{~h}$ in the TCM8594 strain (Fig. 2). This result is corresponding with the FK506 production time course of the wild-type and TCM8594 strains in the production medium because the maximal levels of FK506 were revealed at approximately 6 and 4 days, respectively (data not shown). Indeed, RT-PCR results at the different time points in cultivation accurately showed that the transcript levels of the $t c s B, f k b B$, and $f k b N$ genes had apparently increased in TCM8594 strain. This strongly demonstrated the idea that an increase in an essential gene transcription gives rise to the improvement in FK506 production.

\section{FK506 production in SSF using various substrates}

Various low-cost agricultural wastes were used as substrates to produce FK506 by the TCM8594 strain during SSF. Among the five inexpensive and easily available substrates screened, the maximum FK506 yield (382.7 $\mu \mathrm{g} / \mathrm{g}$ substrate) was achieved with wheat bran (Supplementary Table 2). Comparatively less FK506 was produced with all other substrates, such as rice husk, rice bran, soy flour, and sesame oil cake. This result indicates that wheat bran is the most suitable substrate for producing FK506 in the TCM8594 strain, which may have been due to the fact that 


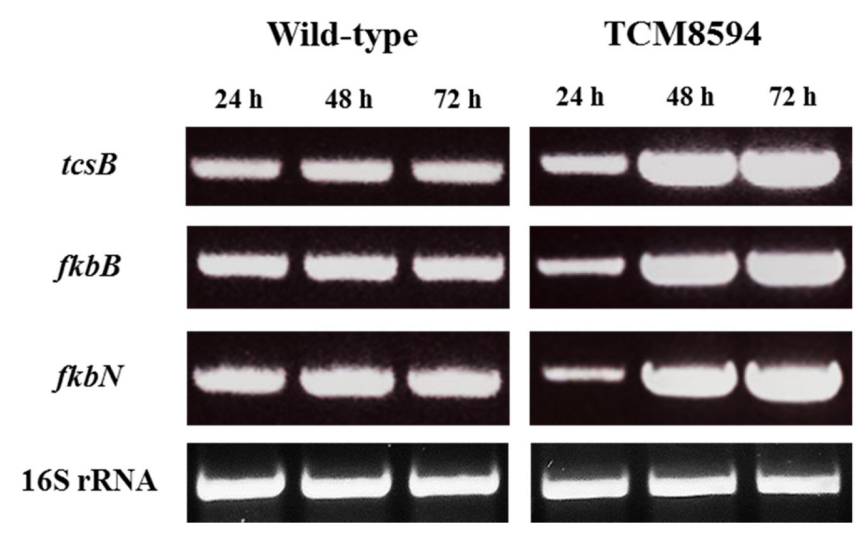

Fig. 2 Gene expression analysis of $t c s B, f k b B$, and $f k b N$ genes by RT-PCR. Analysis was carried out on $S$. tsukubaensis NRRL 18488 and the TCM8594 strain as indicated in Materials and Methods. For transcript analysis of each strain, the experiments were carried out on three independent isolates after 24, 48, and $72 \mathrm{~h}$ of fermentation. The amplified PCR product of $16 \mathrm{~S}$ rRNA gene was served as a control for RNA integrity and loading levels

wheat bran contains sufficient nutrients and remained loose under moist conditions, thereby creating a large surface area (Babu and Satyanarayana 1995). It was previously reported that wheat bran helped to produce the highest titers of tylosin, meroparamycin, and oxytetracycline (El-Naggar et al. 2009; Khaliq et al. 2009; Lazim et al. 2010). However, the wild-type strain produced a very small amount of FK506 during SSF, using five substrates (Supplementary Table 2).

\section{Effect of initial moisture level}

The effect of moisture content of substrate (wheat bran) on FK506 production is shown in Fig. 3A. The maximum FK506 production (523.8 $\mu \mathrm{g} / \mathrm{g}$ substrate) by the TCM8594 strain was accomplished at $70 \%(\mathrm{v} / \mathrm{w})$ moisture content on day 12 of the incubation. When moisture content was lower or higher than $70 \%$ (v/w), FK506 production was low because the substrate was too dry or wet for cell growth and antibiotic production. Improvement of FK506 production was not observed in wild-type strain.

\section{Effect of inoculum level}

To study the influence of inoculum level on FK506 production, various cell concentrations (equivalent to $2,5,7,10,15$, and $20 \%$ $(\mathrm{v} / \mathrm{w})$ cell culture after $72 \mathrm{~h})$ were added to each of six flasks. Fermentations were then performed for 12 days, and the results are presented in Fig. 3B. Higher FK506 titers were obtained at an inoculum level of $10 \%(\mathrm{v} / \mathrm{w})$, and FK506 production by the TCM8594 strain increased up to $654.5 \mathrm{ig} / \mathrm{g}$ substrate on day 12 of incubation. Wild-type strain showed a very small in FK506 yield ( $28.8 \mu \mathrm{g} / \mathrm{g}$ substrate).

\section{Effect of initial pH}

Among the physical parameters occurring during SSF processes, initial $\mathrm{pH}$ of the SSF plays a key role by inducing secondary metabolite production by Streptomyces spp. (Khaliq et al. 2009). The effect of initial substrate $\mathrm{pH}$ on FK506 production is displayed in Fig. 3C. The optimal $\mathrm{pH}$ for maximum FK506 production was $7.2(721.6 \mu \mathrm{g} / \mathrm{g}$ substrate) when grown in SSF. Less FK506 was produced when initial pH was lower or higher than the optimal. In particular, FK506 yield decreased significantly when the initial $\mathrm{pH}$ was adjusted to 8.2 and 9.2. The same FK506 production result was observed for wild-type strain.

\section{Effect of incubation temperature}

Maintaining an optimal process temperature is a major factor and strongly affects the economy of the SSF process. Fermentation temperature affects microbial cell growth, sporulation and germination of spore, and microbial cell physiology; thus, affecting product formation. The optimal temperature for maximum FK506 production by the TCM8594 strain was $30{ }^{\circ} \mathrm{C}(754.6 \mu \mathrm{g} /$ g substrate) (Fig. 3D). The highest FK506 production by wildtype strain was achieved at $30{ }^{\circ} \mathrm{C}$. A similar observation was observed by S. marinensis NUV 5 in SSF by Ellaiah et al. (2004). However, Yang and Ling found that the optimal temperature for Streptomyces viridifaciens for tetracycline production was $26{ }^{\circ} \mathrm{C}$ using sweet potato residue (Yang and Ling 1989). This result indicates that the optimal temperature for antibiotic production is dependent on the test strain.

\section{Effect of incubation times}

Fig. 3E exhibits the influence of incubation time on FK506 production in SSF. Different incubation times were evaluated under optimized conditions $(70 \%(\mathrm{v} / \mathrm{w})$ substrate moisture level, $10 \%(\mathrm{v} / \mathrm{w})$ inoculum, initial $\mathrm{pH} 7.2$, and incubation temperature of $30{ }^{\circ} \mathrm{C}$ ) to study their effect on FK506 production over 12 days. FK506 was produced in the beginning of the exponential growth phase at day 6 of incubation, and maximum FK506 production (806.7 and $39.4 \mu \mathrm{g} / \mathrm{g}$ substrate) occurred on day 10 in the TCM8594 strain and wild-type strain cultures, respectively, after which there were slightly decreases in FK506 production. The most remarkable increase in antibiotic yield was observed during 

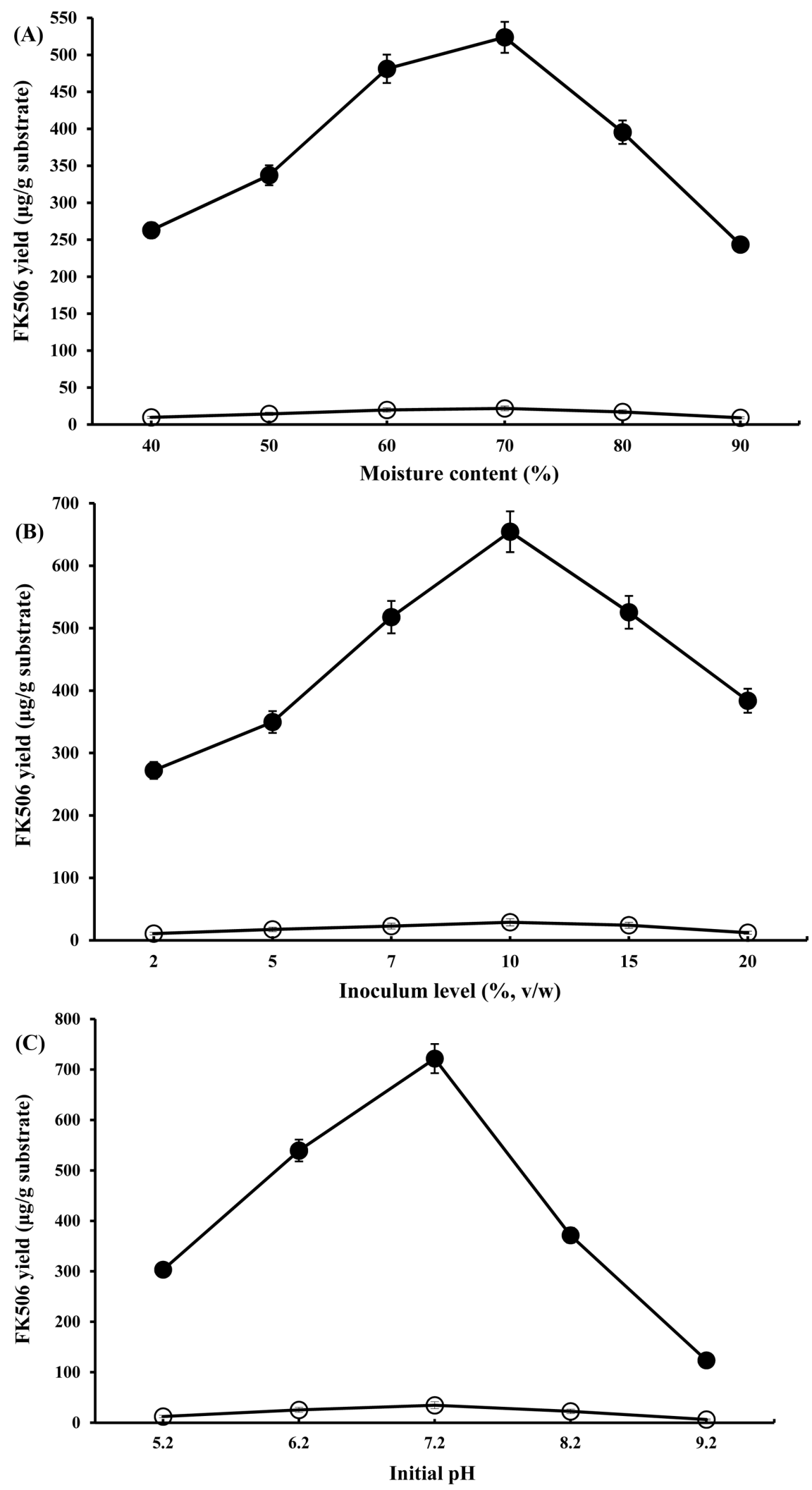

Fig. 3 Effects of various process parameters and additives on FK506 production by S. tsukubaensis NRRL 18488 and the TCM8594 strain under SSF with wheat bran as the substrate. The process parameters were: (A) Initial moisture content, (B) Inoculum level, (C) Inoculum level, (D) Incubation temperature, and (E) Incubation time. Solid circle, FK506 yield by TCM8594 strain; open circle, FK506 yield by S. tsukubaensis NRRL 18488 

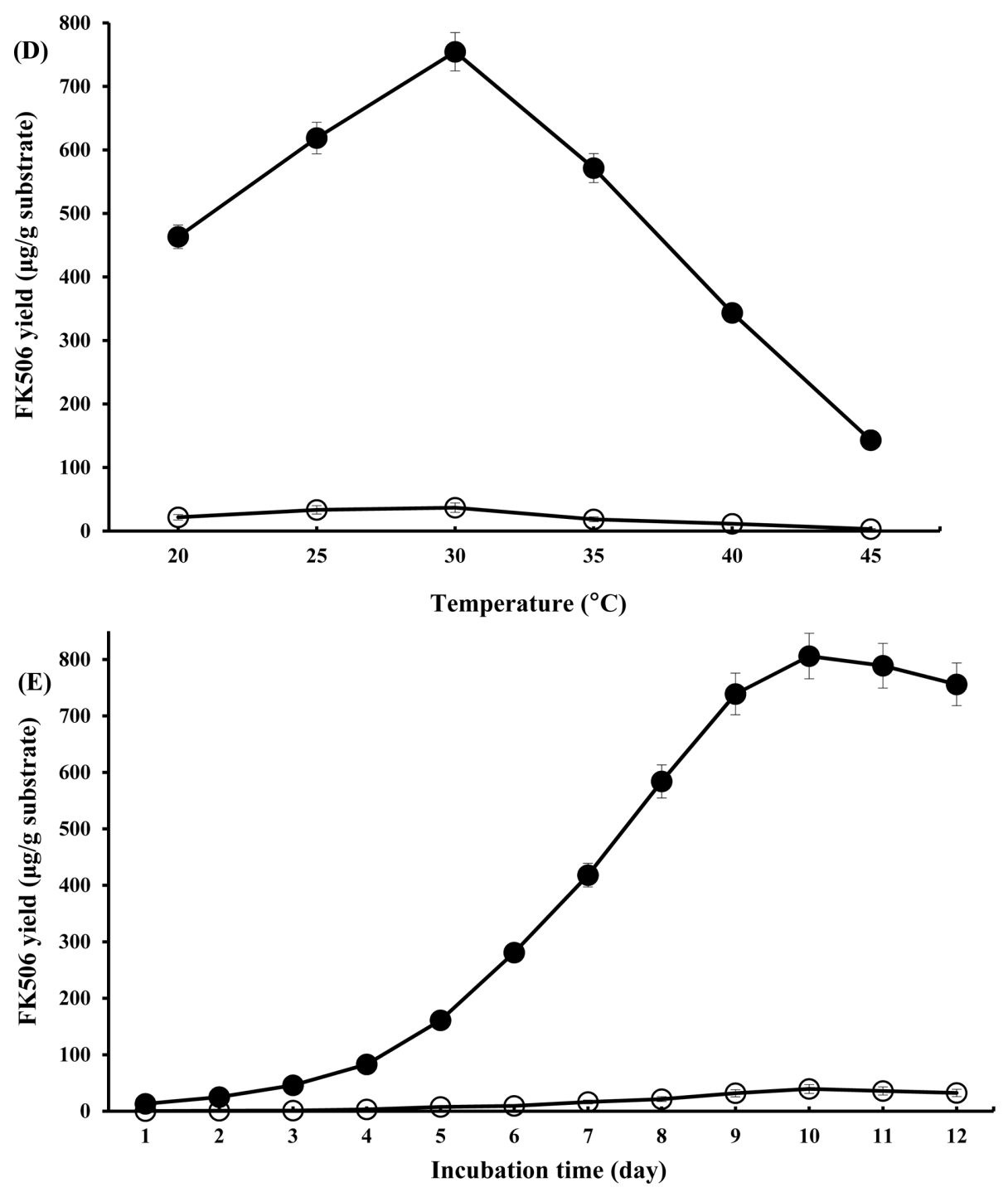

Fig. 3 Continued

SSF between days 8-10 (Ellaiah et al. 2004; Khaliq et al. 2009). However, Kota and Sridhar (1998) reported that production of cephamycin C reached a maximum on day 15 in SSF. Lazim et al. (2010) also reported that oxytetracycline production reaches its maximal value on day 5. This result indicates that optimal production of secondary metabolites depend on the growth kinetics of the microbes.

\section{Effect of additional nutrients}

Although wheat bran can support FK506 production, it may not provide sufficient carbon source for maximum FK506 production by the TCM8594 strain. Hence, adding different carbon sources to the solid medium may enhance FK506 production. We tested the effects of adding glucose, lactose, maltose, mannose, sorbitol, sucrose, starch, and dextrin $(5 \%, \mathrm{w} / \mathrm{w})$, and the results are shown in Fig. 4A. Maximum FK506 production (854.7 $\mu \mathrm{g} / \mathrm{g}$ substrate) was achieved when $5 \%(\mathrm{w} / \mathrm{w})$ dextrin was added to the SSF medium. Starch also increased FK506 yield slightly, whereas glucose, sucrose, lactose, maltose, mannose, and sorbitol decreased FK506 production. These results agree with those reported previously showing that starch and dextrin stimulate FK506 production (Martínez-Castro et al. 2013).

The influence of different organic nitrogen sources on FK506 production was also studied using wheat bran medium supplemented with dextrin, and the results are shown in Fig. 4B. Maximum FK506 yield (897.4 ìg/g substrate) was obtained after adding yeast extract whereas a reduction of FK506 yield was observed when other nitrogen sources were added to the TCM8594 strain culture. This result agrees with that reported previously showing that yeast extract improves the yield of FK506 in S. tacrolimicus B3178 (Singh and Behera 2009). Under the optimum culture conditions, the TCM8594 finally yielded $897.4 \mu \mathrm{g}$ per $\mathrm{g}$ of substrate. This yield is 2.3-fold higher than that obtained in before optimum culture condition (Fig 5A). 

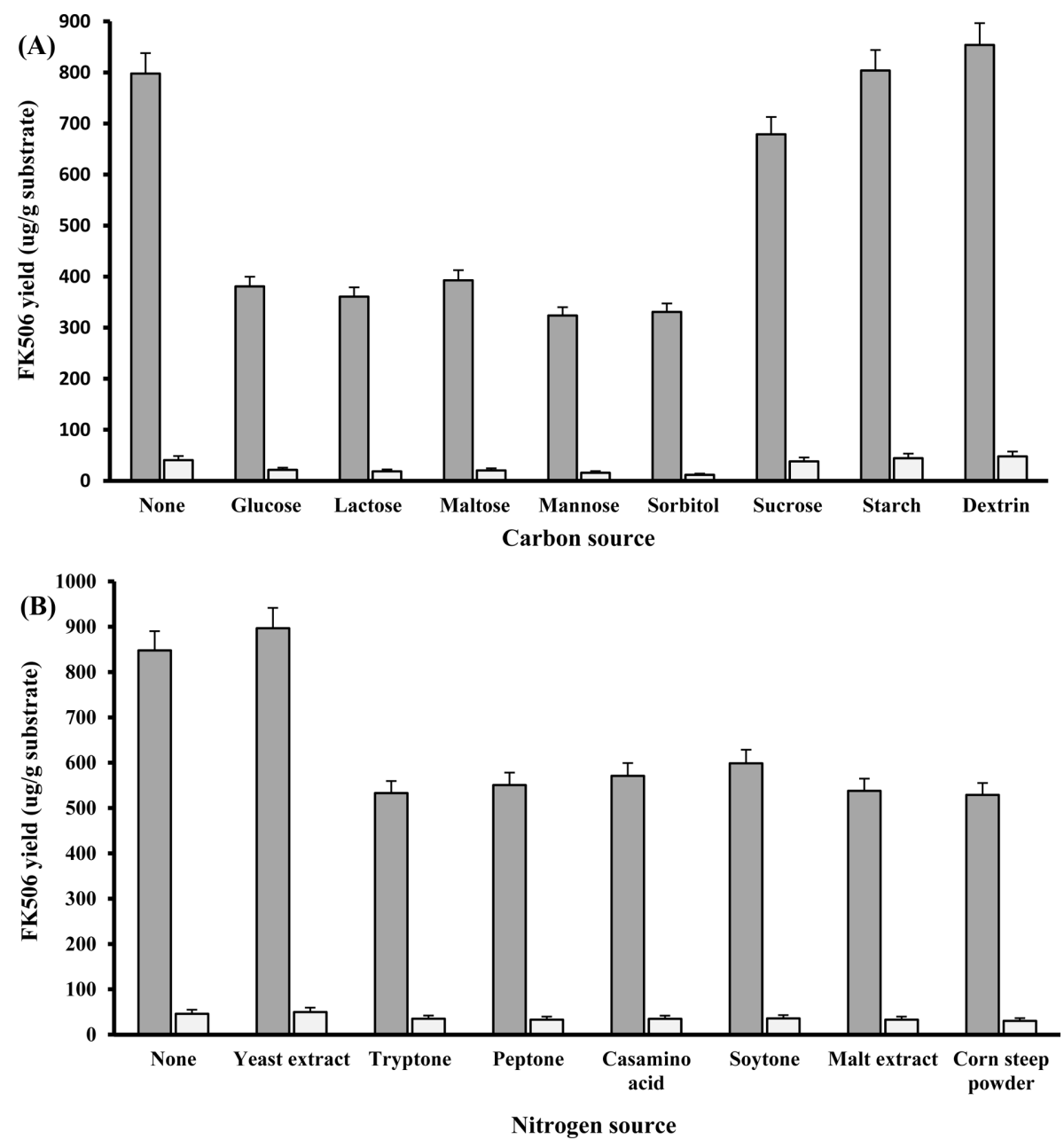

Fig. 4 Effect of various additives on FK506 production. (A) Effect of additional carbon sources in the presence of wheat bran on FK506 production by S. tsukubaensis NRRL 18488 and the TCM8594 strain during SSF. All carbon sources were added at $5 \%$ (w/w). (B) Effect of additional organic nitrogen sources in the presence of wheat bran and dextrin on FK506 production by S. tsukubaensis NRRL 18488 and the TCM8594 strain during SSF. Dark grey, FK506 yield by TCM8594 strain; Light grey, FK506 yield by S. tsukubaensis NRRL 18488. Data are means \pm standard deviations of three independent experiments

\section{Comparisons of antifungal activity of SmF and SSF}

The antifungal activities of extracts against microorganisms were investigated in this study and their potency was evaluated by the diameter of presence inhibition zones. The effect of two different culture systems on FK506 titer against $A$. niger in TCM8594 strain is shown Fig. 5B. For comparison of the antifungal activity of FK506 by SSF and SmF, the dried SmF and SSF extracts were dissolved in methanol to give a final concentration of $100 \mathrm{mg} / \mathrm{mL}$. The clear inhibitory zone of 15 and $20 \mathrm{~mm}$ against $A$. niger was observed for crude FK506 extracted from SmF and SSF. According to the results obtained, the final concentration of SmF and SSF extracts are adjusted similarly, however, extracts of SSF proved to have more antifungal activity against $A$. niger than extracts of SmF. This result showed that effect of the growth inhibition of $A$. niger by the crude extracts depended on fermentation process. Thus, it can be concluded that SSF was more efficient way to increase in the FK506 productivity and titer.
In conclusion, we optimized the SSF conditions to produce FK506 from a TCM8594 strain developed by random mutagenesis and FK506 sequential adaptation. The results clearly indicate that $S$. tsukubaensis TCM8594 can be successfully cultivated under SSF conditions to produce FK506 using wheat bran as the substrate. The maximum FK506 production $(897.4 \mu \mathrm{g} / \mathrm{g}$ substrate) was accomplished by employing wheat bran with dextrin and yeast extract as additional nutrients and with optimized process parameters, such as $70 \%(\mathrm{v} / \mathrm{w})$ initial moisture content, initial $\mathrm{pH} 7.2$, incubation temperature $30{ }^{\circ} \mathrm{C}$, inoculum $10 \%(\mathrm{v} / \mathrm{w})$ cell culture, and incubation time of 10 days. Overall, FK506 production finally increased $234 \%$ after optimizing the process parameters. In addition, antifungal activity shows that comparative advantage of FK506 production under SSF and SmF indicated better production with the SSF technique. Our results show for the first time that high yields of FK506 can be produced using SSF with an improved strain and optimized parameters, and that this is a 


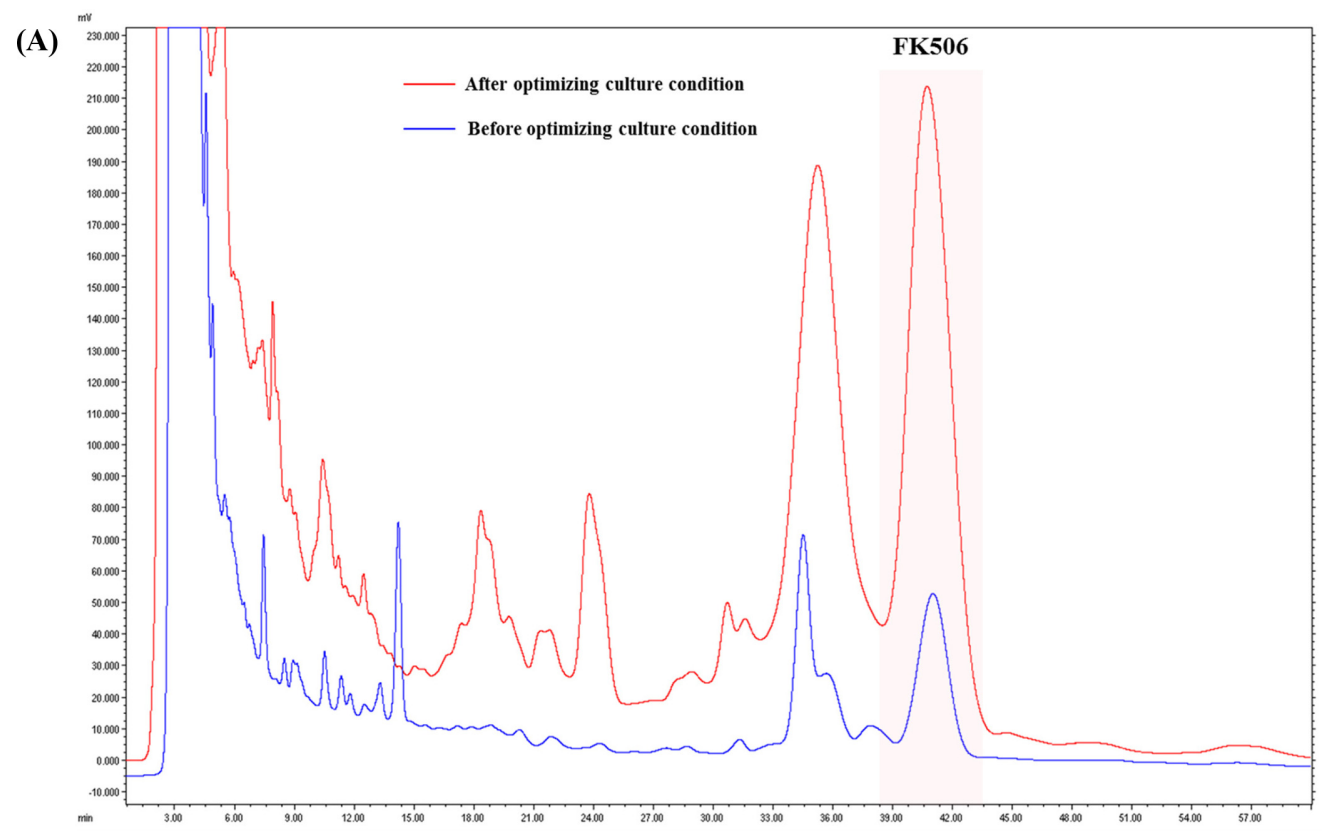

(B)
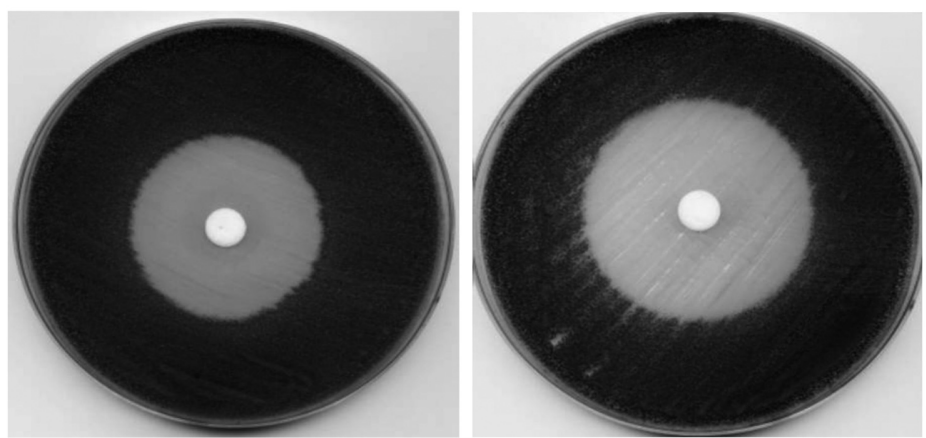

Fig. 5 HPLC trace of FK506 titer after optimizing culture condition and antifungal activity comparision of SmF and SSF. (A) HPLC analyses from methanol extracted solid medium from before optimizing culture condition (blue line) and after optimizing culture condition (red line) The shade indicates the identity of FK506 (in red). Extracted samples were loaded onto a Discovery HS C18 column (Supelco Analytical, USA), which was maintained at $50{ }^{\circ} \mathrm{C}$. The linear elution gradient from 20 to $100 \%$ acetonitrile, the flow rate was $1 \mathrm{~mL} / \mathrm{min}$, and detection was carried out with a UV detector at $205 \mathrm{~nm}$. (B) Antifungal activities of submerged culture (left) and solid culture (right) extracts of TCM8594 were examined against $A$. niger by paper disc diffusion assay. Equal amounts of crude extracts were impregnated and observed for zone of inhibition after 2

good alternative technology to SmF.

Acknowledgments This research was supported by Basic Science Research Program through the National Research Foundation of Korea (NRF) funded by the Ministry of Education (2013R1A1A2013299).

\section{References}

Asagbra AE, Sanni AI, Oyewole OB (2005) Solid-state fermentation production of tetracycline by Streptomyces strains using some agricultural wastes as substrate. World J Microbiol Biotechnol 21: 107114

Babu KR, Satyanarayana T (1995) á-amylase production by thermophilic Bacillus coagulans in solid state fermentation. Process Biochem 30:
305-309

Baltz RH (1986a) Mutagenesis in Streptomyces. In: Demain AL, Soloman NA (eds.) Manual of industrial microbiology and biotechnology. American Society for Microbiology, Washington, DC, pp 184-190

Baltz RH (1986b) Mutagenesis in Streptomyces. In: Queener SW, Day LE (eds.) The bacteria, Vol. 9: Antibiotics-Producing Streptomyces. Academic Press, New York, pp 61-93

Barreiro C, Martínez-Castro C (2014) Trends in the biosynthesis and production of the immunosuppressant tacrolimus (FK506). Appl Microbiol Biotechnol 98: 497-507

Ellaiah P, Srinivasulu B, Adinarayana K (2004) Optimization studies on neomycin production by a mutant strain of Streptomyces marinensis in solid state fermentation. Process Biochem 39: 529-534

El-Naggar MY, El-Assar SA, Abdul-Gawad SM (2009) Solid-state fermentation for the production of meroparamycin by Streptomyces sp. strain MAR01. J Microbiol Biotechnol 19: 468-473

Ghildyal NP, Lonsan BK, Sreekantiah KR, Moorthy VS (1985) Economics of submerged and solid-state fermentations for the production of amyloglucosidase. J Food Sci Technol 22: 171-176 
Haddad EM, McAlister VC, Renouf E, Malthaner R, Kjaer MS, Gluud LL (2006) Cyclosporin versus tacrolimus for liver transplanted patients. Cochrane Database Syst Rev 18: CD005161

Khaliq S, Rashid N, Akhtar K, Ghauri MA (2009) Production of tylosin in solid-state fermentation by Streptomyces fradiae NRRL-2702 and its gamma-irradiated mutant (ã-1). Lett Appl Microbiol 49: 635-640

Kota KP, Sridhar P (1998) Solid state cultivation of Streptomyces clavuligerus for cephamycin C production. J Sci Ind Res 58: 587-590

Lazim H, Slama N, Mankai H, Barkallah I, Limam F (2010) Enhancement of oxytetracycline production after gamma irradiation-induced mutagenesis of Streptomyces rimosus CN08 strain. World J Microbiol Biotechnol 26: $1317-1322$

Lee JC, Park HR, Park DJ, Son KH, Yoon KH, Kim YB, Kim CJ (2003) Production of teicoplanin by a mutant of Actinoplanes teicomyceticus. Biotechnol Lett 25: 537-540

Martínez-Castro M, Salehi-Najafabadi Z, Romero F, Pérez-Sanchiz R, Fernández-Chimeno RI, Martín JF, Barreiro C (2013) Taxonomy and chemically semi-defined media for the analysis of the tacrolimus producer 'Streptomyces tsukubaensis'. Appl Microbiol Biotechnol 97: 2139-2152

Miller J (1983) Mutational specificity in bacteria. Annu Rev Genet 17: 215 238

Mo S, Lee SK, Jin YY, Oh CH, Suh JW (2013) Application of a combined approach involving classical random mutagenesis and metabolic engineering to enhance FK506 production in Streptomyces sp. RM7011. Appl Microbiol Biotechnol 97: 3053-3062

Mo S, Lee SK, Jin YY, Suh JW (2016) Improvement of FK506 production in the high-yielding strain Streptomyces sp. RM7011 by engineering the supply of allylmalonyl-CoA through a combination of genetic and chemical approach. J Microbiol Biotechnol 26: 233-240

Rajoka MI, Akhtar MW, Hanif A, Khalid AM (2006) Production and characterization of a highly active cellobiase from Aspergillus niger grown in solid state fermentation. World J Microbiol Biotechnol 22: 991-998

Singh BP, Behera BK (2009) Regulation of tacrolimus production by altering primary source of carbons and amino acids. Lett Appl Microbiol 49: 254-259

$\mathrm{Xu}$ ZN, Shen WH, Chen XY, Lin JP, Cen PL (2005) A high-throughput method for screening of rapamycin-producing strains of Streptomyces hygroscopicus by cultivation in 96-well microtiter plates. Biotechnol Lett 27: $1135-1140$

Yang SS, Ling MY (1989) Tetracycline production with sweet potato residue by solid state fermentation. Biotechnol Bioeng 33: 1021-1028

Yang T, Li J, Li L, Zhang H, Ma J, Chen Z, Hu C, Ju X, Fu J (2014) Improvement of FK 506 production by selection of 4-Aminobutyric acidtolerant mutant and optimization of its fermentation using response surface methodology. J Korean Soc Appl Biol Chem 57: 715-722 